Fanum

Sociológico

\section{Forum Sociológico}

Série II

$38 \mid 2021$

Número 38

\title{
O gótico também é feminino : Igualdade de género numa subcultura musical
}

The gothic is female too: Gender equality in a musical subculture

\section{Manuel Pereira Soares}

\section{Q OpenEdition}

12 Journals

\section{Edição electrónica}

URL: https://journals.openedition.org/sociologico/9610

DOI: 10.4000/sociologico.9610

ISSN: 2182-7427

\section{Editora}

CICS.NOVA - Centro Interdisciplinar de Ciências Sociais da Universidade Nova de Lisboa

\section{Edição impressa}

Paginação: 15-23

ISSN: 0872-8380

\section{Refêrencia eletrónica}

Manuel Pereira Soares, «O gótico também é feminino : Igualdade de género numa subcultura musical», Forum Sociológico [Online], 38 | 2021, posto online no dia 02 junho 2021, consultado o 29 março 2022. URL: http://journals.openedition.org/sociologico/9610 ; DOl: https://doi.org/10.4000/ sociologico.9610 


\title{
O GÓTICO TAMBÉM É FEMININO \\ IGUALDADE DE GÉNERO NUMA SUBCULTURA MUSICAL*
}

\author{
THE GOTHIC IS FEMALE TOO \\ GENDER EQUALITY IN A MUSICAL SUBCULTURE
}

DOI: https://doi.org/10.4000/sociologico.9610

Manuel Pereira Soares

Universidade de Coimbra, Faculdade de Economia, Coimbra, Portugal. ORCID: https://orcid.org/0000-0003-3057-3283

\begin{abstract}
Resumo
Neste texto aborda-se a desigualdade de género no campo cultural, com especial incidência na música. Cruzando diversos estudos que abordam este tema, afigura-se relevante perceber se existem exceções à desigualdade de género no campo musical, algo que algum trabalho feito internacionalmente indicia, como sucede com o caso do gótico. Procurando verificar se esta subcultura constitui, de facto, uma exceção à tendência existente para a desigualdade de género na música, procede-se à análise da composição do cartaz das dez edições do festival Entremuralhas, único festival gótico em Portugal. A observação permite concluir pela existência de uma maior igualdade em termos estatísticos nesta subcultura em comparação com outros géneros musicais; contudo, não é possível, apenas com estes dados, aferir se essa maior igualdade é efetivamente sentida no dia a dia das mulheres.
\end{abstract}

Palavras-chave: subcultura gótica, igualdade de género, música

\begin{abstract}
In this paper, we want to examine gender inequality in the cultural field, with a special focus on music. Given several studies dealing with this topic, it seems relevant to find out if there are exceptions, especially in the musical field, as some internationally conducted studies have already pointed out, as in the case of the Gothic subculture. In an attempt to verify whether this alternative culture is an exception to the existing tendency towards gender inequality in music, we analyze the composition of the line-ups of ten editions of the Entremuralhas festival, the only Gothic festival in Portugal. The observation allows us to conclude that there is greater gender equality in statistical terms in this subculture compared to other musical genres, but it is not possible with these data alone to determine whether this greater gender equality is noticeable in the daily lives of women.
\end{abstract}

Keywords: gothic subculture, gender equality, music

\section{Introdução}

As mulheres sentem na sua vida quotidiana os efeitos da discriminação, tendo maiores dificuldades de inserção no mercado de trabalho, deparando-se com barreiras no acesso a certas profissões e vendo dificultadas as possibilidades de construir uma carreira a par com os seus congéneres masculinos.
No campo da cultura, que, por princípio, devia ser menos suscetível a replicar essas desigualdades (Pujar 2016), estas questões também se fazem sentir. As oportunidades continuam a não ser iguais para mulheres e homens. A música é disso um claro exemplo. Do punk (Berkers, 2012; Reddington, 2004) e do rock and roll (Berkers, 2012; Frith e McRobbie, 1990) ao heavy metal (Berkers e Schaap, 2018), mas

* O autor utiliza o novo acordo ortográfico. 
não esquecendo o jazz (Grieve, 2018; Shriver, 2018) e a música clássica (The Scotsman, 2017), todos os géneros musicais parecem replicar a masculinização do setor. Essa desigualdade não passa apenas pela maior dificuldade em integrar grupos, mas inclui as diversas atividades profissionais relacionadas com o mundo da música, que reserva as posições mais subalternas e menos específicas para as mulheres, conferindo aos homens os papéis centrais (Pujar, 2016). Contudo, no caso da subcultura gótica, a igualdade entre homens e mulheres parece assumir-se como uma marca identitária. Sendo uma subcultura com diversas subdivisões em estilos musicais, uma análise mais abrangente permite concluir que, pelo menos em termos estatísticos, ela é mais feminina que os restantes géneros musicais, como parecem atestar trabalhos efetuados anteriormente para o caso do gothic metal (Berkers e Schaap, 2018, p. 57).

A questão do género, enquanto elemento socialmente construído, não se consegue libertar de certa complexidade, e esta divisão torna-se presente quando se procura atribuir características às mulheres. Perceciona-se que elas são mais emocionais (De Boise, 2016) e que, portanto, serão mais ligadas às atividades do cuidar, relegando-as para as tarefas associadas à interação social e afastando-as das atividades mais físicas e técnicas (Berkers, Verboord e Weij, 2016, p. 521).

Importa refletir sobre a desigualdade nas indústrias culturais, de que são exemplos a música, a edição de livros e jornais, a rádio, a televisão e o cinema, por exemplo. O campo das desigualdades nestes domínios é vasto, e os estudos que têm sido feitos comprovam-no. Encontram-se trabalhos que incidiram sobre as desigualdades no campo literário (Tuchman e Fortin, 1984; Verboord, 2012), na indústria dos filmes (Bielby e Bielby, 1996; Pujar, 2016) e no campo da música (Berkers 2012; Berkers e Eeckelaer, 2014; Berkers e Schaap, 2018; Krenske e McKay, 2000; Leonard, 2007; Martins, 2012; Osazuwa, 2010).

Embora constituindo, em muitos casos, a maioria da força de trabalho nas indústrias culturais, e Portugal não constitui exceção (INE, 2016), a mulher depara-se com dificuldades várias para aceder a certas atividades (Magalhães e Alvarez, 2014), contrariando a ideia de que o mundo da arte é um campo de liberdade e mais propício para contornar as barreiras assentes em discriminações de género (Pujar, 2016). A menor presença de mulheres em determinadas profissões, como sucede com algumas muito técnicas, como a dos mecânicos, eletricistas e especialistas de Tecnologias de Informação, por exemplo, faz-se também sentir em Portugal (Coelho e Ferreira, 2018, p. 90).

\section{Desigualdades na cultura e na música}

O mundo da música é fortemente marcado por uma desigualdade entre homens e mulheres que não se manifesta apenas ao nível da formação das bandas. Leonard, por exemplo, atribui ao facto de o jornalismo musical ser maioritariamente composto por homens a explicação para a maior cobertura dada aos artistas masculinos (Leonard, 2007, p. 29).

O sexismo da indústria musical começa nos papéis que se atribuem às mulheres. No âmbito daquilo que são os mundos da arte de Becker, e da ideia de pessoal auxiliar (2010), as atividades em que as mulheres mais trabalham na indústria musical são as de relações públicas e estilista. As groupies, por sua vez, consubstanciam uma personificação do imaginário do artista masculino sempre rodeado de mulheres (Hesmondhalgh e Baker, 2015).

O mundo da música, especialmente o do rock and roll e suas derivações, é assumido como sendo masculino. Angela McRobbie e Simon Frith exploram muito bem esta questão no seu texto sobre o rock e a sexualidade quando recordam que, em termos de controlo e produção, o rock é eminentemente uma forma masculina, que tem como principais atores homens e onde a sexualidade desempenha um papel importante, realçando a faceta dominadora do homem e a subordinação da mulher (Frith e McRobbie, 1990, pp. 320-321). Mesmo nos casos da música de dança e da música pop, assiste-se a uma forma discriminatória de tratar um e outro. Segundo Thornton, assume-se que as raparigas têm menor conhecimento da música, uma vez que consomem menos, leem menos imprensa especializada e saem menos que os rapazes; por isso, a elas se associa o "baixo entretenimento feminizado", ao passo que à música que ouvem os rapazes é associada a "alta arte virilizada" (Thornton, 1995). Por outro lado, na música pop, onde parecem existir mais casos de mulheres com um papel relevante na indústria da música, existe o chamado ciclo de vida das artistas. Ele funciona enquanto elas se dispõem a seguir o modelo padronizado da sexualização da sua imagem, fazendo com que este seja dos fatores mais importantes para o negócio. Mais do que o talento para cantar, escrever letras ou compor, parece interessar vender a imagem, como se observa nos vídeos das músicas, onde a mulher traja o mínimo de roupa possível, ao passo que o homem vende a sua música mantendo-se vestido (Lieb, 2018, pp. 69-71).

Assim se entende que a imprensa especializada dê tanto destaque a uma presença feminina no seu meio. Os vários números especiais de revistas e jornais musicais dedicados às mulheres do rock, já de si ilustrativo de que se trata, na ótica daqueles jornalistas, de um feito especial (Leonard, 2007, p. 32), parecem reforçar esta ideia de excecionalidade. 
O rock transforma-se, assim, numa certa cultura coletiva de homens, um mundo masculino partilhado de colegas, fãs e músicos, onde a mulher sente grandes dificuldades em entrar (Frith e McRobbie, 1990, p. 321). Se tal sucede, é porque os principais atores do negócio da música, responsáveis por controlar quem pode ou não entrar, quem tem ou não direito a ser promovido ou divulgado, são homens (Frith e McRobbie, 1990; Lieb, 2018).

Embora os trabalhos sobre o desequilíbrio de representação entre homens e mulheres na música incidam, por norma, no rock and roll, esta desigualdade faz-se sentir igualmente noutros géneros. Num trabalho realizado sobre os dez maiores festivais de música nos EUA, que englobam os mais diferentes géneros musicais, constata-se que, embora $51 \%$ do público sejam mulheres, as bandas compostas unicamente por homens que neles participam apresentam-se em percentagens que variam entre um mínimo de $66 \%$ e um máximo de $93 \%$; e os casos em que as bandas são mistas variam entre valores perto do zero até um máximo em torno dos $30 \%$, dependendo do festival em análise (Vagianos, 2016). No caso da música clássica, as mulheres sentem visíveis dificuldades em atingir a posição de maestrina, por exemplo, e a sua representação nas orquestras é muito inferior ao que seria expectável, tendo em conta o número de mulheres que estudam música e composição nas universidades (The Scotsman, 2017). O caso do jazz afigura-se como sendo um dos que apresentam maior dificuldade para atingir a igualdade (Grieve, 2018). Embora seja comum encontrar intérpretes femininas neste género musical, são menos de $5 \%$ as instrumentistas mulheres (Shriver, 2018). É também no jazz que mais pesa a ideia dos instrumentos culturalmente masculinos, como trompete, trombone, guitarra e baixo que estão praticamente vedados às mulheres; na ausência de modelos, elas sentem-se desincentivadas a optar por um instrumento, escolhendo, na sua maioria, tornar-se vocalistas (Grieve, 2018; Shriver, 2018). Estes desequilíbrios já motivaram, inclusivamente, várias tomada de posição pública vindas de dentro de algumas organizações ligadas ao jazz, alertando e propondo algumas medidas para lidar com o problema (EJN, 2018).

A indústria da música é, portanto, maioritariamente dominada por homens. Em 870 artigos analisados na revista musical Loud, apenas $8 \%$ continham referências a mulheres (Martins, 2012, p. 192). Em dois exercícios para tentar apurar a presença de mulheres no mundo da música, analisaram-se enciclopédias musicais de 1977 a 2001 e as tabelas de vendas de 1974 a 2000, tendo-se concluído que, no primeiro caso, as mulheres (a solo ou como membros de bandas) representavam um intervalo de $8 \%$ a $22 \%$ de todas as entradas registadas, enquanto, no segundo estudo, a análise das tabelas de vendas de sete países permitiram apurar que das 3375 entradas registadas $60 \%$ referiam-se aos mesmos cinquenta artistas, dos quais apenas três eram mulheres. Estas análises revelaram que, na esmagadora maioria dos casos, essas mulheres assumiam ou o papel de cantoras ou o de cantoras-letristas, observando-se muito poucos casos de bandas centradas em mulheres, cujo protagonismo fosse delas (Leonard, 2007, p. 28).

Se utilizarmos o punk como exemplo, o qual, pelo seu carácter revolucionário e contestatário, pressuporia maior igualdade, observamos que a desigualdade de género também aí se manifesta (Berkers, 2012; Reddington, 2004). A tentativa de as mulheres se afirmarem artisticamente através do punk parece ter sido esquecida. Este tipo de música, e todo o movimento em si, tido como violento e agressivo, afasta-se do estereótipo das características femininas, o que poderá explicar a maior dificuldade de as mulheres se afirmarem no punk. O facto de as raparigas aprenderem na escola instrumentos mais femininos, como piano e guitarra clássica, afastava-as da típica tríade instrumental do punk constituída por bateria, guitarra elétrica e baixo (Reddington, 2004). Em Portugal, Paula Guerra tem dado atenção ao tema da desigualdade de género na música, especialmente na cena punk, desvendando a dificuldade que as mulheres têm em desfazer estereótipos e libertar-se dos papéis de subjugação ao masculino que sentem neste meio (Guerra, Bittencourt e Gelain, 2018; Guerra e Gelain, 2017). O movimento Riot Grrrls, surgido no início dos anos 90, ao fundir o punk com o feminismo, funcionou como tentativa de dar essa voz às mulheres e confrontar o sexismo existente na música e na sociedade (Guerra, Bittencourt e Gelain, 2018; Haenfler, 2010).

Mas é quando chegamos ao heavy metal que a desigualdade entre géneros se faz notar de forma mais extrema (Walser, 1993). Se atentarmos aos diversos subgéneros do metal, como black metal, trash metal, death metal, speed metal, etc., percebemos a forte componente masculina que se pretende imprimir a esta música, pautada por ser violenta, barulhenta, agressiva, rápida (Berkers e Schaap, 2014, 2015, 2018; Berkers, Verboord e Weij, 2016; Krenske e McKay, 2000).

O mundo do heavy metal é masculino e a subjugação feminina é uma constante. Toda a estética, letras, linguagem e práticas corporais valorizam a masculinidade e ajudam a denegrir as mulheres e os gays (Krenske e McKay, 2000, p. 290); o meio torna-se assim campo fértil para o afastamento das mulheres, que são vistas como intrusas, seres deslocados. O stage-diving e o mosh, práticas que consistem em, literalmente, mergulhar na turba de espectadores a partir do palco e dançar de forma violenta, inibem as mulheres de participar neles. 
Isso sucede, em primeiro lugar, porque os homens veem estes rituais como uma coisa masculina ${ }^{1}$, e, em segundo, porque as mulheres se arriscam a ser importunadas sexualmente, com os homens a aproveitar a confusão para as apalpar (Krenske e McKay, 2000). Assim sendo, às mulheres é reservado um papel secundário e mais recatado, deixando aos homens a tarefa de se colocarem em frente ao palco e praticarem os rituais do metal (Berkers e Schaap, 2018). As letras, imagens dos discos e atitudes também são discriminatórias. É frequente que as $T$-shirts das bandas tenham imagens bastante erotizadas de mulheres. Títulos de músicas como Hooks in You ou Bring your daughter to the slaughter, que podemos encontrar no álbum No Prayer for the Dying dos Iron Maiden, uma das referência do heavy metal, ilustram bem esta realidade (Leonard, 2007, p. 25).

A segregação e os muitos estereótipos tornam difícil as mulheres fazerem parte do meio musical. Para contornar essas dificuldades, as mulheres utilizam as plataformas digitais para participarem, sem necessidade de uma banda ou de uma sala de espetáculos. Recorrendo ao Youtube, filmam-se a cantar ou a tocar e colocam os vídeos online, esperando que o público reaja (fazendo comentários ou críticas) e que algum responsável de uma editora ou uma banda as convide para integrar um projeto musical (Berkers e Schaap, 2014, 2015). Mesmo à distância, as mulheres são alvo de discriminação, que se traduz em comentários de índole sexista, como, por exemplo, "para rapariga, até tocas bem" (Berkers e Schaap, 2015, p. 305), ou avaliações, não à performance, mas ao aspeto físico (Berkers e Schaap, 2014); além disso, existem muito mais comentários de carácter técnico (com sugestão de correções) feitos às mulheres do que aos homens (Berkers e Schaap, 2015).

Por serem uma minoria, as mulheres tornam-se mais notadas no heavy metal, quer nos espetáculos ao vivo, quer na internet. Na vertente online, para aumentarem a sua visibilidade, elas optam por identificar os vídeos com a tag female, garantindo, dessa forma, que conseguem mais visualizações (Berkers e Schaap, 2014). Neste caso, aproveitam para jogar a seu favor o conhecimento de que o meio é masculino.

Existe a ideia estereotipada, e que vem já desde a Idade Média, de que existem uns instrumentos mais femininos e outros mais masculinos, e que se se relaciona com aquilo que se convencionou serem as características do homem (agressividade, vigor físico) e da mulher (suavidade, delicadeza) (Steblin, 2013). Embora o decurso do tempo tenha permitido que alguns instrumentos se tornassem mais "femininos", como sucedeu, em certa medida, com o piano e outros instrumentos da mesma família (Steblin, 2013), a estereotipização permanece ainda hoje, como se pode observar nos estudos feitos com orquestras de escolas secundárias e de universidades nos EUA; estes estudos concluem que, embora se assista a um aumento considerável de mulheres nas orquestras, os instrumentos que elas escolhem continuam a ser os "femininos", isto é, clarinete, flauta, violino, havendo poucas a optarem por instrumentos "masculinos" (Zervoudakes e Tanur, 1994).

No rock and roll, as guitarras são vistas como símbolos fálicos, as letras são, por vezes, arrogantes e toda a atuação conduz à ideia de agressividade, domínio e presunção; os intérpretes parecem querer relembrar à assistência quem é que "controla" (Frith e McRobbie, 1990, p. 319). Outros instrumentos, como o violino e os sintetizadores, são tidos como mais femininos. O facto de o gothic metal recorrer com frequência a eles torna a sua música mais melódica e suave, menos agressiva, podendo assistir-se a uma maior participação de mulheres neste subgénero do metal (Berkers e Schaap, 2018).

\section{Alguns apontamentos sobre o movimento gótico}

O pós-punk, ainda no final dos anos 70, vai trazer um conjunto de novas expressões musicais, mais elaboradas e mais melódicas (Newman, 2018). Algumas destas novas bandas direcionam o foco da contestação que o punk apontava à sociedade para a introspeção e para a abordagem dos problemas e vivências pessoais. Contudo, na génese, estas bandas não eram góticas. O termo, aliás, só será cunhado anos mais tarde (Carramolino, 2013; Siegel, 2005).

Mais do que musical, o movimento gótico define-se por se associar a diversas formas de expressão, como sejam a literatura, as artes plásticas e a moda, e as suas influências vão também colher inspiração à literatura gótica, ao culto dos vampiros, aos filmes de terror, às culturas pagãs, célticas e egípcias, e às praticas sexuais menos convencionais como o sadomasoquismo, o bondage e dominação, e ainda ao queer e ao drag (Goodland e Bibby, 2007, p. 2), isto é, tudo o que fuja à normalidade. Também por isso, por esta vontade de aceitar o que não é considerado normal, o gótico será um meio propício para acolher todos aqueles que têm dificuldade em se inserir noutros movimentos.

A presença feminina é uma marca do gótico desde o seu início. Siouxsie Sioux, uma das figuras maiores desta subcultura, é mulher, tal como outros nomes que desempenharam um papel relevante nalgumas das bandas seminais da cena: Rose McDowall (Sorrow), Anne Marie Hurst (Skeletal Family), Gitane Demone (Christian Death), Jarboe (Swans), Monica Richards (Faith and the Muse) e Anka Wolbert (Clan of Xymox), (Kilpatrick, 2005; 
Matzke, Seeliger e Stieg, 2000, 2002; Roberts, Livingstone e Baxter-Wright, 2016).

Ainda assim, também no gótico as grandes referências são homens ou bandas quase exclusivamente compostas por homens. Evoluindo para um som melancólico, depressivo e mais melódico, bandas como Joy Division, Bauhaus, The Cure e Siouxsie and the Banshees, que constituem as chamadas quatro grandes (big four), estão na génese daquilo que viria a transformar-se na música gótica e afastam-se da estridência e agressividade do punk, de onde eram provenientes, para criar uma nova sonoridade (Kilpatrick, 2005, pp. 79-81). Ao longo da sua evolução, o gótico irá subdividir-se em vários ramos diferentes, como o darkwave, darkambient, darkfolk, coldwave, gothic metal, gohic rock, cybergoth, etc., contando todos eles com significativa presença de mulheres, embora mais nuns casos do que noutros; no darkfolk/ neofolk, por exemplo, predominam os homens e o papel das mulheres é esquecido (Diesel, Gerten e Wolff, 2013, pp. 104-105).

O facto de os góticos recorrerem a maquilhagem e assumirem, ou tentarem assumir, um aspeto andrógino vai também marcar uma diferença relativamente à desigualdade de género que os outros estilos musicais promovem. Esta androginia é, inclusivamente, uma marca distintiva da subcultura, que pretende exercer a igualdade de género, não de forma a mesclar ambos os sexos, mas a feminizá-los, pelo que a transformação do masculino em feminino consegue granjear capital subcultural, ao contrário da transformação do feminino em masculino, que é desvalorizada nesta subcultura (Brill, 2008).

A questão visual assume grande importância como forma de marcar o desalinhamento com a norma, e os góticos optam por uma forma diferente de vestir e de se maquilhar, provocando a sociedade e subvertendo o instituído. Para os góticos, o visual afigura-se como algo identitário e não apenas uma certa forma de carnavalização, como parece suceder com outros estilos, como o black metal, visualmente muito espetacular nos concertos, mas que os seus membros não adotam no dia a dia (Matzke, Seeliger e Stieg, 2000, p. 83).

O gothic metal, quando comparado com o heavy metal, revela uma maior presença de mulheres. A subcultura gótica apresenta-se como tolerante e não faz discriminações com base no género (Goulding, Saren, Maclaran e Follett, 2004), o que torna mais fácil para as mulheres integrarem-se nos vários tipos de música presentes nesta subcultura. Inclusivamente, o movimento tende a romper com as fronteiras normativas da ordem heterossexual, quando os representantes masculinos enveredam por uma certa feminização ou androginia no visual adotado (Niekrenz, 2019).

\section{Metodologia}

Partindo da ideia de que o gótico conta também com mulheres, procura-se confirmar esta premissa através de alguns dados. Para tal, observam-se as bandas que integraram as dez edições do festival gótico Entremuralhas realizadas entre 2010 e 2019 em Leiria². A pesquisa baseou-se nos métodos de análise de diferentes trabalhos sobre a igualdade de género na música e incidiu sobre três aspetos: 1. perceber a percentagem de bandas com presença de mulheres, seguindo o método encontrado em Marion Leonard (2007) e Vagianos (2016); 2. perceber qual a percentagem que as mulheres representam no total do universo de artistas das bandas participantes no festival, seguindo o critério de Berkers e Schaap utilizado para o universo do heavy metal (Berkers e Schaap, 2018); 3. perceber se os instrumentos tocados pelas mulheres são mais "femininos" ou "masculinos", na senda de alguns trabalhos sobre o género e instrumentos musicais (Bayton, 1988; Berkers, 2012; Berkers e Schaap, 2018; Zervoudakes e Tanur, 1994). Teria sido interessante poder apurar também a participação das mulheres em outras funções, como as de letrista e compositora, por exemplo, mas tal não foi possível, pois a maior parte das bandas desta subcultura não disponibiliza essa informação nos seus sites oficiais (nos casos em que eles existem), ou nas informações que constam do material que acompanha os discos.

Para poder ter uma forma de comparação, recorreu-se a alguns dados de referência que foram obtidos através do levantamento bibliográfico efetuado para a produção deste texto. No livro de Berkers e Schaap (2018, p. 56) a percentagem de mulheres identificadas no total dos artistas no gothic metal é de $17 \%$, o mais elevado entre todos os subgéneros do heavy metal. Nesse sentido, em comparação com o gótico numa aceção mais ampla, havia a expectativa de que a percentagem feminina apurada nas análises superasse este valor. Abaixo disso significaria que a maior presença feminina no gothic metal constituía uma exceção específica desse subgénero.

Outro valor que serviu de referência foi retirado do livro de Marion Leonard (2007, p. 28) e referia-se à percentagem de entradas de bandas com pelo menos um membro feminino nas enciclopédias e guias musicais de 1977 até 2001, e que foi de $22 \%$. Tendo em conta que este número era respeitante a bandas de todos os géneros musicais, esta percentagem permitiria saber se o nível de participação de mulheres nas bandas góticas era superior ou inferior ao que se verifica na música em geral. Uma última análise procurou saber quais as funções (vocalista ou instrumentista) que mais vezes as mulheres ocupam no gótico e se o estereótipo de género também se 
reproduz na escolha do instrumento, como sucede noutros géneros musicais.

\section{Os resultados}

Da análise dos cartazes das dez edições do festival Entremuralhas, constatou-se que foram anunciadas 126 bandas, tendo-se retirado dez por não se ter conseguido encontrar registos das suas atuações no festival ${ }^{3}$. A percentagem de bandas com participação de pelo menos uma mulher na sua formação é de $50,9 \%$, o que, quando comparado com os $22 \%$ de mulheres nos vários géneros musicais referidos na obra de Leonard (2007), resulta num valor significativamente superior no caso do gótico. Interessa ainda destacar que, embora com participação em mais de metade das bandas, apenas 2,6\% destas são exclusivamente compostas por mulheres, ao passo que $49,1 \%$ são totalmente compostas por homens e $48,3 \%$ são mistas (Tabela 1 ).

Outra informação que se procurou descortinar foi o papel assumido pelas mulheres nas bandas, ou seja, se desempenhavam a função de frontgirl (o elemento ou elementos da banda sobre quem recai o protagonismo). O critério para saber se um elemento era ou não frontgirl baseou-se nos textos de apresentação das bandas no site do festival, em informações dos sites oficiais das bandas e através da visualização de vídeos das atuações no Entremuralhas. A análise permite concluir que em $64 \%$ dos casos as mulheres assumem o papel de frontgirl, ou seja, são as protagonistas da banda.

Interessava depois perceber qual a percentagem efetiva de mulheres em todo o universo em análise. Contabilizou-se o número de artistas que integraram as bandas participantes nas dez edições do festival, chegando-se a um total de 396. Desse universo,
$318(80,3 \%)$ eram homens e $78(19,7 \%)$ mulheres (Tabela 2); tendo como referência a percentagem de $17 \%$ de mulheres no gothic metal identificada no estudo de Berkers e Schaap (2018), verifica-se uma diferença pouco significativa neste estudo, o que conduz à conclusão de que no gótico, quando contemplados os seus diferentes estilos, existem ligeiramente mais mulheres que apenas no gothic metal.

Assim sendo, e após estas análises, conclui-se que a hipótese de o gótico ter uma maior igualdade de género na constituição dos seus grupos se revela verdadeira, o que certamente estará relacionado com a própria história da subcultura, que permitiu sempre às mulheres um papel relevante. Ainda assim, estes dados apenas permitem depreender uma igualdade estatística.

Um último exercício propunha-se verificar que funções as mulheres nas bandas (vocalistas ou instrumentistas) assumem mais vezes, tendo em conta a estereotipização de papéis e instrumentos que é transversal a toda a indústria da música, e à qual se foi aludindo ao longo deste texto. Neste sentido, fez-se um levantamento de todas as mulheres que participaram no festival e verificou-se qual o papel que assumiram nas bandas ${ }^{4}$. Concluiu-se que uma larga maioria ocupa a função de vocalista (56\%), sendo a guitarra, as teclas, a percussão e o violino os instrumentos mais frequentemente tocados (Gráfico 1). De salientar ainda que, ao agrupar os instrumentos na classificação estereotipada de femininos (teclas, violino, violoncelo, harpa e saltério) e masculinos (guitarra, baixo, percussão), se verifica um certo equilíbrio nessa distribuição ( $21 \%$ e $23 \%$, respetivamente), com uma ligeira vantagem para os instrumentos dito masculinos; contudo, essa diferença não permite afirmar que, neste aspeto,

Tabela $1 \triangleright$ Caracterização das bandas por tipo de presença (só homens, só mulheres ou mista)

Presença de mulheres

\begin{tabular}{l|c|c|r|r} 
& Frequência & Percentagem & Percentagem válida & $\begin{array}{r}\text { Percentagem } \\
\text { cumulativa }\end{array}$ \\
\hline Fem. & 3 & 2,586 & 2,586 & 2,586 \\
Masc. & 57 & 49,138 & 49,138 & 51,724 \\
Mista & 56 & 48,276 & 48,276 & 100,000 \\
Total & 116 & 100,000 & & \\
\hline
\end{tabular}

Tabela $2 \downarrow$ Número de mulheres e homens no total de artistas participantes no festival gótico Entremuralhas 2010-2019

\begin{tabular}{l|c|c|c|r} 
& Frequência & Percentagem & Percentagem válida & $\begin{array}{r}\text { Percentagem } \\
\text { cumulativa }\end{array}$ \\
\hline Homens & 318 & 80,303 & 80,303 & 80,303 \\
Mulheres & 78 & 19,697 & 19,697 & 100,000 \\
Total & 396 & 100,000 & & \\
\hline
\end{tabular}


Gráfico $1 \triangleright$ Mulheres participantes no festival Entremuralhas entre 2010 e 2019 por função e instrumento

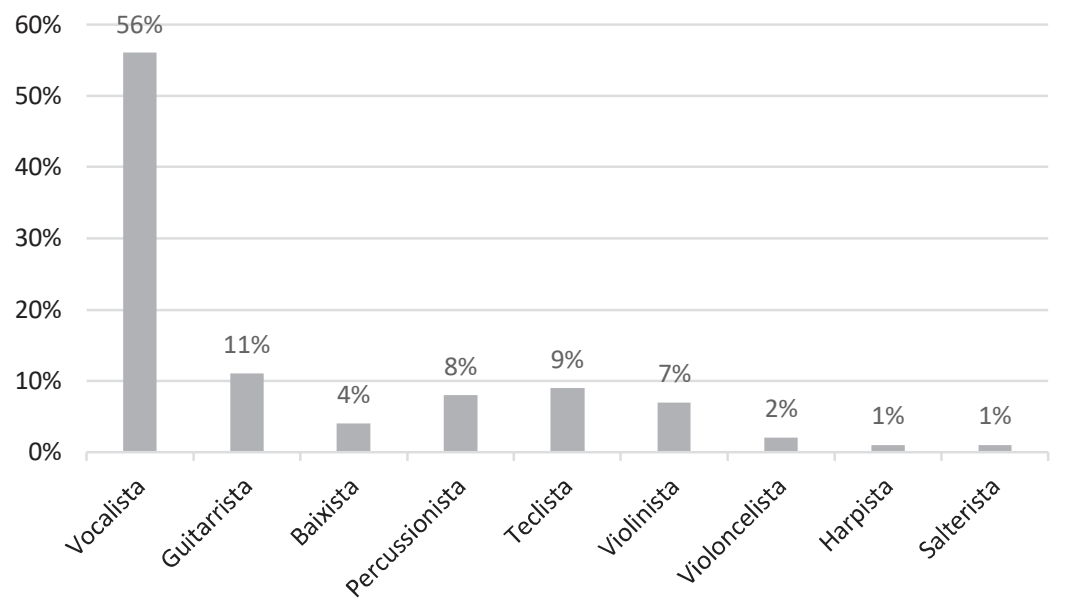

existe marcadamente uma diferença de género relativamente aos instrumentos escolhidos.

\section{Limitações do estudo}

Embora os dados resultantes desta análise permitam afirmar estatisticamente que o gótico é também feminino, não há dados suficientes que possibilitem extrapolar essa igualdade estatística para uma efetiva igualdade no seio desta subcultura. É notório o maior número de mulheres que integram bandas pertencentes ao gótico. A percentagem do número total de artistas que constituem este universo também é superior ao de outros estudos, verificando-se ainda que existe alguma preferência pelos instrumentos ditos "masculinos", o que também traça diferenças em comparação com outros géneros musicais. Contudo, tendo trabalhado apenas com dados quantitativos, seria necessário um estudo de carácter qualitativo que permitisse clarificar a forma como estas mulheres vivem, ou não, esta igualdade de género. Seria interessante saber, por exemplo, se elas sentem essa igualdade no tratamento da cobertura mediática que Ihes é feita, se existe ou não a erotização da sua figura, como sucede noutros estilos musicais, se os públicos rececionam da mesma forma bandas com mulheres e sem mulheres, e se este equilíbrio se mantém também na própria subcultura quando a análise se estende aos públicos dos concertos e espetáculos.

\section{Considerações finais}

Com este texto procurou abordar-se questões relacionadas com a desigualdade de género, especialmente nos domínios da música e da cultura. A literatura indica que essa desigualdade existe de forma vincada e que se manifesta das mais diversas formas. O campo cultural, que à partida devia ser mais propício a uma menor desigualdade assente no género, revela-se também pouco equilibrado, com uma forte masculinização das mais diversas áreas e atividades.

O caso da música revela-se também profundamente desigual, especialmente em géneros como o heavy metal e o rock and roll. O papel das mulheres no campo musical tem tendência a ser relevado para segundo plano; a cobertura da imprensa especializada dá preferência aos grupos e artistas masculinos e isso reflete-se numa menor relevância das mulheres.

A subcultura gótica, especialmente através das suas diversas manifestações musicais, oferece maiores possibilidades de integração e de protagonismo às mulheres. A análise dos cartazes das dez edições já realizadas do festival gótico Entremuralhas permitiu concluir isso mesmo, com participações de mulheres nos casos estudados superiores a $50 \%$ e distribuídas pelas várias funções possíveis.

Embora a comunidade gótica se assuma como um espaço neofeminino (Brill, 2008, p. 329), poder ir mais além e perceber se essa maior igualdade é apenas estatística ou se ela acontece também no dia a dia das mulheres que integram esta subcultura poderia funcionar como um complemento importante para este estudo.

\section{Notas}

$195 \%$ dos participantes no mosh e no stage-diving são masculinos (Krenske e McKay, 2000, p. 298).

2 A análise contemplou todas as bandas que atuaram nas dez edições do festival, independentemente de elas próprias se considerarem ou não integrantes da subcultura, tendo em conta que foram convidadas para participar num festival gótico. 
3 Este estudo consistiu na análise de vídeos das atuações no festival Entremuralhas das bandas anunciadas, para determinar o número de homens e mulheres que constituíam o universo de artistas. Em dez casos não foram encontrados esses registos vídeo, o que se terá devido, com forte probabilidade, ao facto de essas bandas não terem chegado a atuar, pois ao longo das edições houve alguns cancelamentos. Desta forma, estas dez bandas foram excluídas do estudo.

4 O número obtido de 107 vocalistas e instrumentistas, superior às 78 mulheres identificadas no universo total de artistas, justifica-se por haver casos em que a mesma pessoa canta e executa um instrumento.

\section{Referências bibliográficas}

Bayton, M. (Ed.) (1988). How women become musicians (pp. 201-219). Routledge Ebsco Publishing.

Becker, H. (2010). Mundos da arte. Livros Horizonte.

Berkers, P. (2012). Rock against gender roles: Performing femininities and doing feminism among women punk performers in the Netherlands, 1976-1982. Journal of Popular Music Studies, 24(2), 155-175.

Berkers, P., \& Eeckelaer, M. (2014). Rock and roll or rock and fall? Gendered framing of the rock and roll lifestyles of Amy Winehouse and Pete Doherty in British broadsheets. Journal of Gender Studies, 23(1), 3-17.

Berkers, P., \& Schaap, J. (2014). Grunting alone? Online gender inequality in extreme metal music. I@J, 4(1), 101-116.

Berkers, P., \& Schaap, J. (2015). YouTube as a virtual springboard: Circumventing gender dynamics in offline and online metal musica careers. Metal Music Studies, 1(3), 303-318.

Berkers, P., \& Schaap, J. (2018). Gender inequality in metal music production. Emerald Publishing.

Berkers, P., Verboord, M., \& Weij, F. (2016). "These critics (still) don't write enough about women artists": Gender inequality in the newspaper coverage of arts and culture in France, Germany, the Netherlands, and the United States, 1955-2005. Gender \& Society, 30(3), 515-536.

Bielby, D. D., \& Bielby, W. T. (1996). Women and men in film gender inequality among writers in a culture industry. Gender and Society, 10(3), 248-270.

De Boise, S. (2016). Contesting 'sex' and 'gender' difference in emotions through music use in the UK. Journal of Gender Studies, 25(1), 66-84.

Brill, D. (2008). Goth culture: Gender, sexuality and style. BERG.

Carramolino, E. C. (2013). El anhelo de lo prohibido. Ian Curtis y Joy Division, las dos caras de una misma moneda. La transición del post-punk al gothic rock. Desde The Sex Pistols hasta Siouxsie \& The Banshees. Herejía y belleza - Revista de estudios culturales sobre el movimiento gótico, $1,313-332$.

Coelho, L, \& Ferreira, V. (2018). Segregação sexual do emprego em Portugal no último quarto de século
- Agravamento ou abrandamento?. e-cadernos CES, (29), 77-98.

Diesel, A., Gerten, D., \& Wolff, M. (2013). Looking for Europe: The history of neofolk. Index Verlag.

EJN. (2018). EJN members commit to embracing gender balance in the jazz sector. Europe Jazz Network. https://www.europejazz.net/press-release/ejn-members-commit-embracing-gender-balance-jazz-sector

Frith, S., \& McRobbie, A. (Eds.) (1990). Rock and sexuality. Em On Record. Rock, pop and the written word (pp. 317-333). Routledge Ebsco Publishing.

Goodland, C. M. E., \& Bibby, M. (2007). Undead goth subculture. Duke University Press.

Goulding, C., Saren, M., Maclaran, P., \& Follett, J. (2004). Into the darkness: Androgyny and gender blurring within the gothic subculture. GCB - Gender and Consumer Behavior, 7, 1-27.

Grieve, L. (2018). Sexism in jazz. Cherwell. https:// cherwell.org/2018/06/16/sexism-in-jazz/

Guerra, P., Bittencourt, L., \& Gelain, G. (2018). "Punk fairytale": Popular music, media, and the (re)production of gender. Advances in Gender Research, $26,49-68$

Guerra, P., \& Gelain, G. (2017). Corpetes, pulseiras e batons: Género e diferença na cultura punk em Portugal e no Brasil. Em G. Diógenes, L. Dabul, P. Guerra \& P. Costa (Eds.), I Congresso Internacional Lusófono Todas as Artes/Todos os Nomes - Livro de Atas (pp. 49-66). Universidade do Porto. Faculdade de Letras.

Haenfler, R. (2010). Goths, gamers, and grrrls: Deviance and youth subcultures. Oxford University Press.

Hesmondhalgh, D., \& Baker, S. (2015). Sex, gender and work segregation in the cultural industries. Sociological Review, 63(S1), 23-36.

INE. (2016). Estatísticas da cultura aumentou a população empregada nas atividades culturais e criativas (pp. 1-13). https://www. ine.pt/xportal/xmain?xpid=INE\&xpgid=ine destaques\&DESTAQUESdest_boui $=25041983 \overline{2}$ \&DESTAQUESmodo $=2$.

Kilpatrick, N. (2005). The Goth Bible: A compendium for the darkly inclined. Plexus.

Krenske, L., \& McKay, J. (2000). Hard and heavy: Gender and power in a heavy metal music subculture. Gender, Place and Culture, 7(3), 287-304

Leonard, M. (2007). Gender in the music industry. Ashgate Publishing Limited.

Lieb, K. (2018). Gender, branding, and the modern music industry: The social construction of female popular music stars ( $2^{\text {nd }}$ ed.). Routledge.

Magalhães, S. I., \& Alvarez, T. (2014). Mulheres e media. APEM - Associação Portuguesa de Estudos sobre as Mulheres.

Martins, I. R. (2012). Female fronted metal: Um pseudogénero musical para a marginalização da mulher artista?. Em M. do R. G. Santos \& E. M. Lessa 
(Eds.), Música, discurso, poder (pp. 185-200). Universidade do Minho.

Matzke, P., Seeliger, T., \& Stieg, E. (Eds.) (2000). Gothic ( $2^{\text {nd }}$ ed.). Schwarzkopf \& Schwarzkopf.

Matzke, P., Seeliger, T., \& Stieg, E. (Eds.) (2002). Gothic II ( $2^{\text {nd }}$ ed. $)$. Schwarzkopf \& Schwarzkopf.

Newman, S. (2018). The evolution of the perceptions of the goth subculture. Johnsons and Wales University.

Niekrenz, Y. (2019). Boys in black, girls in punk. Gender performances in the goth and hardcore punk scenes in Northern Germany. Em A. Bennett \& P. Guerra (Eds.), DIY cultures and underground music scenes (pp. 63-73). Routledge.

Osazuwa, C. 2010. Gender inequality in the Rock \& Pop music industry: Breaking the glass ceiling. http:// christineosazuwa.com/portfolio/gender-inequality-in-the-rock-pop-music-industry-breaking-the-glass-ceiling/.

Pujar, S. (2016). Gender inequalities in the cultural sector. Culture Action Europe.

Reddington, H. (2004). The forgotten revolution of female punk musicians in the 1970s. Peace Review, 16(4), 439-444.

Roberts, C., Livingstone, H., \& Baxter-Wright, E. (2016). Goth: The design, art and fashion of a dark subculture. Carlton Books.

Shriver, L. (2018). Jazz is dominated by men. So what?. The Spectator. https://www.spectator. co.uk/article/jazz-is-dominated-by-men-so-what-
Siegel, C. (2005). Goth's dark empire. Indiana Press.

Steblin, R. (2013). The gender stereotyping of musical instruments in the Western tradition. Canadian University Music Review, 16(1), 128-144.

The Scotsman. (2017). Music: Fighting the gender inequality in classical music. https://www.scotsman.com/whats-on/arts-and-entertainment/ music-fighting-gender-inequality-classical-music-1442659.

Thornton, S. (1995). Club cultures music, media and subcultural capital. Polity Press.

Tuchman, G., \& Fortin, N. E. (1984). Fame and misfortune: Edging women out of the great literary tradition. American Journal of Sociology, 90(1), 72-96.

Vagianos, A. (2016). Music festivals have a glaring woman problem. Here's why. The Huffington Post. http://data.huffingtonpost.com/music-festivals.

Verboord, M. (2012). Female bestsellers: A cross-national study of gender inequality and the popularhighbrow culture divide in fiction book production, 1960-2009. European Journal of Communication, 27(4), 395-409.

Walser, R. (1993). Running with the Devil: Power, gender, and madness in heavy metal music. University Press of New England.

Zervoudakes, J., \& Tanur, J. N. (1994). Gender and musical instruments: Winds of change?. Journal of Research in Music Education, 42(1), 58-67.

Esta obra está licenciada com uma Licença Creative Commons Atribuição - 4.0 (CC BY 4.0).

Recebido a 15/10/2019. Aceite para publicação a 05/08/2020.

Manuel Pereira Soares

Faculdade de Economia, Universidade de Coimbra, Coimbra, Portugal. Email: manuelpsoares@gmail.com 